\title{
Article \\ Discovery of Novel Dihydrolipoamide S-Succinyltransferase Inhibitors Based on Fragment Virtual Screening
}

\author{
Chengqian Wei, Junjie Huang, Yu Wang, Yifang Chen, Xin Luo, Shaobo Wang, Zengxue Wu and Jixiang Chen *
}

check for

updates

Citation: Wei, C.; Huang, J.; Wang,

Y.; Chen, Y.; Luo, X.; Wang, S.; Wu, Z.;

Chen, J. Discovery of Novel

Dihydrolipoamide

S-Succinyltransferase Inhibitors

Based on Fragment Virtual Screening.

Int. J. Mol. Sci. 2021, 22, 12953.

https://doi.org/10.3390/

ijms222312953

Academic Editor: Lorenzo Lo Muzio

Received: 18 October 2021

Accepted: 25 November 2021

Published: 30 November 2021

Publisher's Note: MDPI stays neutral with regard to jurisdictional claims in published maps and institutional affiliations.

Copyright: (c) 2021 by the authors. Licensee MDPI, Basel, Switzerland. This article is an open access article distributed under the terms and conditions of the Creative Commons Attribution (CC BY) license (https:// creativecommons.org/licenses/by/ $4.0 /)$
State Key Laboratory Breeding Base of Green Pesticide and Agricultural Bioengineering, Key Laboratory of Green Pesticide and Agricultural Bioengineering, Ministry of Education, Center for Research and Development of Fine Chemicals, Guizhou University, Huaxi District, Guiyang 550025, China; wcq1996@163.com (C.W.); hjj18744902440@163.com (J.H.); gs.wy20@gzu.edu.cn (Y.W.); gs.chenyf20@gzu.edu.cn (Y.C.); gs.xunluo20@gzu.edu.cn (X.L.); wangshaobo97@163.com (S.W.); wuzx@gzu.edu.cn (Z.W.)

* Correspondence: jxchen@gzu.edu.cn

Abstract: A series of new oxadiazole sulfone derivatives containing an amide moiety was synthesized based on fragment virtual screening to screen high-efficiency antibacterial agents for rice bacterial diseases. All target compounds showed greater bactericidal activity than commercial bactericides. 3-(4-fluorophenyl)-N-((5-(methylsulfonyl)-1,3,4-oxadiazol-2-yl)methyl)acrylamide (10) showed excellent antibacterial activity against Xanthomonas oryzae pv. oryzae and Xanthomonas oryzae pv. oryzicola, with $\mathrm{EC}_{50}$ values of 0.36 and $0.53 \mathrm{mg} / \mathrm{L}$, respectively, which were superior to thiodiazole copper (113.38 and $131.54 \mathrm{mg} / \mathrm{L})$ and bismerthiazol (83.07 and $105.90 \mathrm{mg} / \mathrm{L})$. The protective activity of compound 10 against rice bacterial leaf blight and rice bacterial leaf streak was $43.2 \%$ and $53.6 \%$, respectively, which was superior to that of JHXJZ (34.1\% and $26.4 \%)$ and thiodiazole copper (33.0\% and $30.2 \%$ ). The curative activity of compound 10 against rice bacterial leaf blight and rice bacterial leaf streak was $44.5 \%$ and $51.7 \%$, respectively, which was superior to that of JHXJZ $(32.6 \%$ and $24.4 \%)$ and thiodiazole copper $(27.1 \%$ and $28.6 \%)$. Moreover, compound 10 might inhibit the growth of Xanthomonas oryzae pv. oryzae and Xanthomonas oryzae pv. oryzicola by affecting the extracellular polysaccharides, destroying cell membranes, and inhibiting the enzyme activity of dihydrolipoamide S-succinyltransferase.

Keywords: antibacterial activity; fragment; virtual screening; DLST inhibitors

\section{Introduction}

Rice bacterial diseases threaten global food security due to their high frequency, serious damage, and difficulty to prevent and control [1-3]. Among them, rice bacterial leaf blight (RBLB) and rice bacterial leaf streak (RBLS), caused by Xanthomonas oryzae pv. oryzae (Xoo) and Xanthomonas oryzae pv. oryzicola $(X o c)$, are two extremely destructive bacterial diseases that can cause $20-50 \%$ loss of agricultural production $[4,5]$. Today, traditional commercial bactericides, such as bismerthiazol and thiodiazole copper, are used to control RBLB and RBLS [6]. However, the long-term repeated use of traditional commercial bactericides has caused the control effect of bacteria to decrease and serious pollution to the environment to increase year by year [7-9], hence there is an urgent need for their replacement with new bactericides [10]. Therefore, the discovery of novel antibacterial agents is presently an urgent problem.

The research and development of new drugs is a long and complicated process, which requires significant resources and time costs. According to the report of the Tufts Center for the Study of Drug Development, the development of a new drug requires an average of 10-15 years, USD 1.4 billion in resource costs, and USD 1.16 billion in time costs [11,12]. As a mature drug design method, virtual screening to find candidate compounds has become the main method of drug design [13]. Fragment-based drug discovery (FBDD) could explore a larger chemical space through a smaller number of fragment compounds, 
discover molecules with higher binding efficiency, reduce the cost of drug development, and improve the efficiency of drug development $[14,15]$. Therefore, the fragment-based virtual screening guided discovery of new drugs is a research hotspot in the field of plant protection.

In our previous work, we found the sulfone candidate antibacterial agent JHXJZ [16]. Dihydrolipoamide $S$-succinyltransferase (DLST) was verified to be the target of JHXJZ by the click chemistry and quantitative chemical proteomic approach $[17,18]$. In this work, based on DLST, a model was established by rapidly identifying the non-effect fragments, thereby selectively replacing and optimizing the affinity of the drugs. A series of compounds was designed and synthesized, and some candidate drugs were selected. Then, their antibacterial activities against rice bacterial diseases were evaluated, and their mechanism of action was initially explored.

\section{Results}

\subsection{Molecular Design}

JHXJZ was dismantled into fragments and their ligand efficiency (LE) was evaluated. Fragment a was chosen due to its better binding free energy $(\Delta G)$. Because changing the number of carbon atoms in the sulfone had a significant impact on the affinity, we chose compounds a1 and $\mathbf{a} 2$ (core $\mathbf{1}$ and core $\mathbf{2}$ ) as promising starting core fragments for lead compound generation. Structure-based fragment virtual screening was conducted on core 1 and $\mathbf{2}$ in combination with DLST. Soon afterwards, the top 10 candidates with favorable $\Delta G$ values of the two core fragments were obtained. According to the feasibility of the synthesis and purification of the fragments, we considered whether it was possible to further synthesize and optimize. The six fragments were synthesized out together and the result showed that most of the fragments had excellent bactericidal activity except for the pyridine fragments. We believed that this type of structure had further enhanced value in the later stage, for instance, fragments 119 and 612. Finally, fragments were determined according to the feasibility of the synthesis and derivatization of the fragments. Additionally, based on the combination mode of the fragments, we performed a singlereplacement optimization scan and further optimized multiple-replacement optimization for the derivation of new compounds. From the later experimental results, compounds 24, 10, and 16, which showed better bactericidal activity, had become the candidates. The construction process of this model based on DLST is shown in Figure 1.

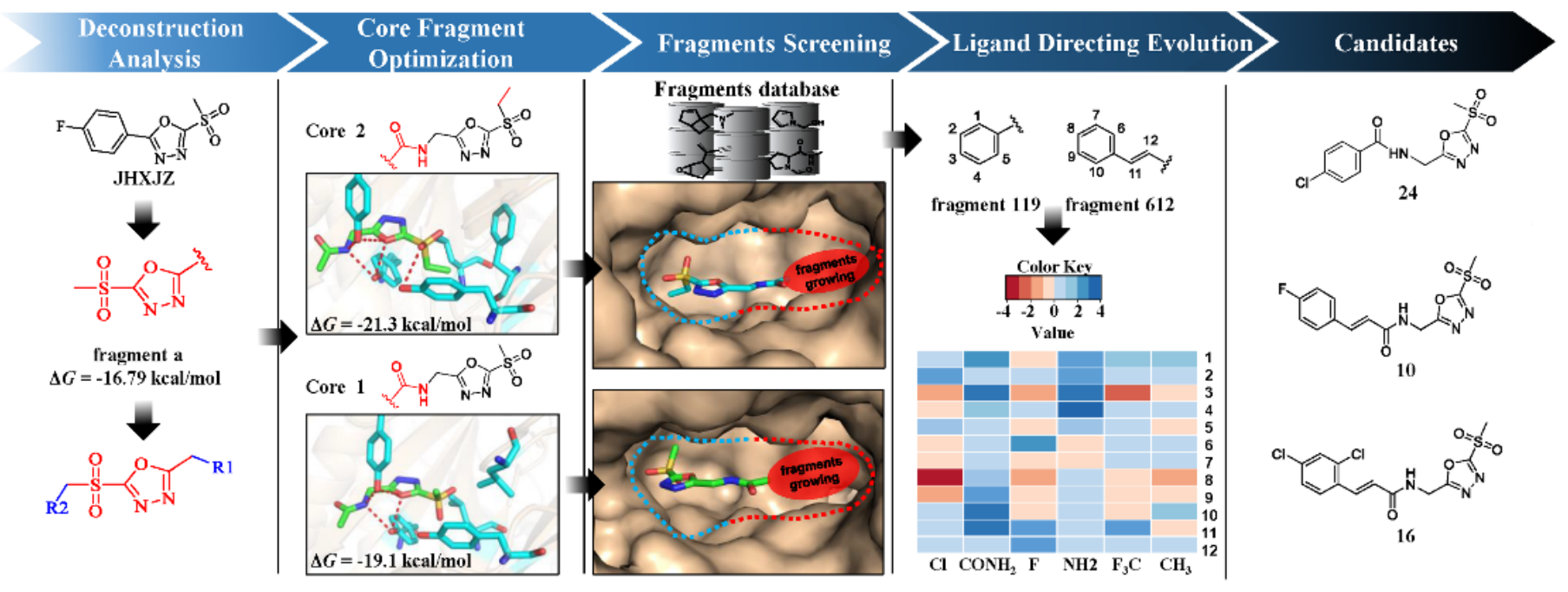

Figure 1. The fragment-based virtual screening: the structural optimization of JHXJZ.

DLST was verified as the target of JHXJZ by the click chemistry and quantitative chemical proteomic approach. Therefore, we performed the fragment-based virtual screening based on JHXJZ (Figure 2). We found that the binding mode of JHXJZ was important 
to the structure-based lead optimization, and we predicted the binding mode of JHXJZ with DLST through molecular docking (Figure 2). Then, we analyzed the binding mode of JHXJZ to identify a prioritized pharmacophore. The stability of the binding mode was confirmed by a 10 ns molecular dynamic simulation. For DLST and JHXJZ, the binding mode was in an extended conformation and located in a hydrophobic pocket. Moreover, JHXJZ could form a hydrogen bond with ARG407, ALA410, and LYS178, and then form a halogen bond with GLU33. The JHXJZ bound away from the hydrophobic region that consisted of Arg180, Arg407, and Arg636.

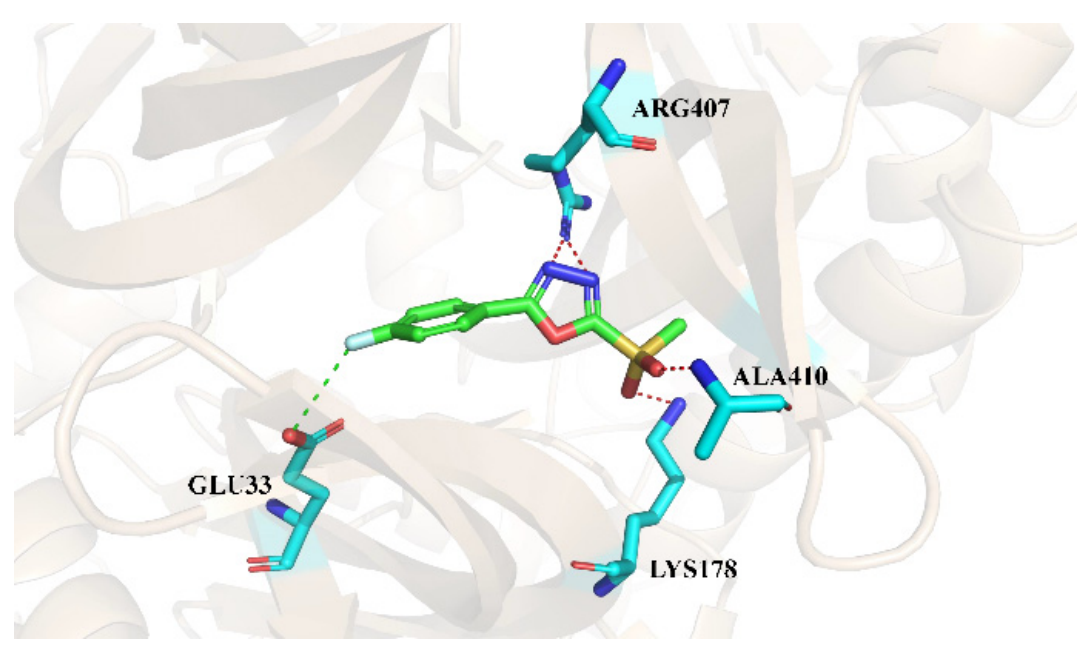

Figure 2. The binding mode of JHXJZ.

Based on the binding mode of JHXJZ, we deconstructed JHXJZ into fragments and evaluated their ligand efficiency (LE). The binding free energy $(\Delta G)$ was determined using the Molecular Mechanics/Poisson-Boltzmann Surface Area (MM/PBSA) (Table 1). Fragment a showed the lowest binding free energy and the highest ligand efficiency $(\Delta G=-16.79 \mathrm{kcal} / \mathrm{mol}, \mathrm{LE}=1.87)$. Fragment $\mathbf{c}$ showed the lowest ligand efficiency and the highest binding free energy $(\Delta G=-6.55 \mathrm{kcal} / \mathrm{mol}, \mathrm{LE}=0.81)$. Hence, fragment $\mathrm{c}$ was a portion incapable of contributing binding free energy, and the compound showed modification potential for structural evolution. The structural modification was performed on fragment a to optimize binding affinity. Typically, the addition of non-bond interactions and hydrophobic interactions can effectively improve the affinity (Table 2). It was noticed that changing the number of carbon atoms in the sulfone had a significant impact on the affinity $(\mathbf{a} 1, \Delta G=-19.11 \mathrm{kcal} / \mathrm{mol}, \mathrm{LE}=1.47 ; \mathbf{a} 2, \Delta G=-21.31 \mathrm{kcal} / \mathrm{mol}, \mathrm{LE}=1.52)$. Therefore, we chose compounds a1 and a2 (core $\mathbf{1}$ and core 2 ) as promising starting core fragments for lead compound generation.

Table 1. The deconstruction analysis of JHXJZ.

\begin{tabular}{cccc}
\hline Compound & Structure & LE \\
\hline JHXJZ & & 1.60 \\
\hline
\end{tabular}


Table 1. Cont.

\begin{tabular}{clll}
\hline Compound & Structure & $\Delta G$ & LE \\
\hline $\mathrm{C}$ & & -6.55 & 0.81 \\
$\mathrm{~d}$ & & -7.67 & 1.53 \\
\hline
\end{tabular}

Table 2. The optimization analysis of compound a.

Compound

Structure-based fragment virtual screening was conducted on core $\mathbf{1}$ and $\mathbf{2}$ in combination with DLST. All linked fragments were refined. The top 10 candidates with favorable $\Delta G$ values of the two core fragments were obtained (Table 3). According to the feasibility of the synthesis and purification of the fragments, we considered whether it was possible to further synthesize and optimize. In the process of screening the fragments, we tried to synthesize the target compounds. The six fragments were synthesized out together and the result showed that most of fragments had excellent bactericidal activity except for the pyridine fragments (Table 4). Among them, according to the feasibility of the synthesis and derivatization of the fragments, we believed that fragments 119 and $\mathbf{6 1 2}$ had the potential for further optimization. To further optimize the binding free energy of compounds 9 and 11, the ligand-directing evolution strategy was performed using the AILDE web server. A series of compounds was generated based on compounds 9 and 11, and the top 10 candidates with favorable $\Delta \Delta G$ values are shown in the Supplementary Materials. In total, 26 compounds were synthesized by ranking the binding energy and synthetic accessibility, and the antibacterial activity of all the target compounds was evaluated (Tables 4, S1 and S2). 
Table 3. The fragment structure generated from core 1 and 2 via ACFIS webserver.

\begin{tabular}{|c|c|c|c|c|c|}
\hline Fragment & Structure & $\Delta G$ & Fragment & Structure & $\Delta G$ \\
\hline core1 & & -19.11 & core2 & & -21.31 \\
\hline 858 & & -29.69 & 677 & & -31.70 \\
\hline 677 & & -28.15 & 1247 & & -30.59 \\
\hline 612 & & -27.48 & 288 & & -29.36 \\
\hline 1247 & & -26.55 & 858 & & -29.19 \\
\hline 119 & & -26.44 & 1347 & & -28.85 \\
\hline 708 & & -26.15 & 119 & & -28.76 \\
\hline 1347 & & -26.02 & 612 & & -28.71 \\
\hline 1523 & & -26.01 & 260 & & -28.65 \\
\hline 1549 & & -24.94 & 254 & & -27.81 \\
\hline 266 & & -24.58 & 1549 & & -27.47 \\
\hline
\end{tabular}

Table 4. The six screened fragments.

\begin{tabular}{|c|c|c|c|c|c|}
\hline Number & Compound & Fragment & $n$ & $\Delta G$ & $\mathrm{EC}_{50}$ \\
\hline 1 & 1 & & 0 & -29.69 & 0.68 \\
\hline 2 & 2 & & 1 & -29.19 & 0.72 \\
\hline 3 & 3 & & 0 & -28.15 & 0.53 \\
\hline 4 & 4 & & 1 & -31.70 & 0.45 \\
\hline 5 & 5 & & 0 & -26.55 & 0.48 \\
\hline 6 & & & 1 & -30.59 & - \\
\hline 7 & 6 & & 0 & -24.94 & 3.49 \\
\hline 8 & 7 & & 1 & -27.47 & 7.45 \\
\hline 9 & 8 & & 0 & -27.48 & 0.73 \\
\hline 10 & 9 & & 1 & -28.71 & 0.89 \\
\hline 11 & & & 0 & -26.44 & - \\
\hline 12 & & & 1 & -28.76 & - \\
\hline
\end{tabular}


Among target compounds 1-26, compounds 24, 10, and 16 showed better bactericidal activity. The binding modes of JHXJZ and compounds 24, 10, and 16 against DLST are shown in Figure 3. Compared to the binding mode of JHXJZ, compounds 24, 10, and 16 formed hydrogen bonds with TYR195 and TRY422, and formed pi stacking with TYR195. In addition, a stronger hydrophobic interaction was formed due to molecular collisions with Arg180/407/636. We believe that this computational framework might be used to eliminate non-effect fragments and optimize binding affinity.

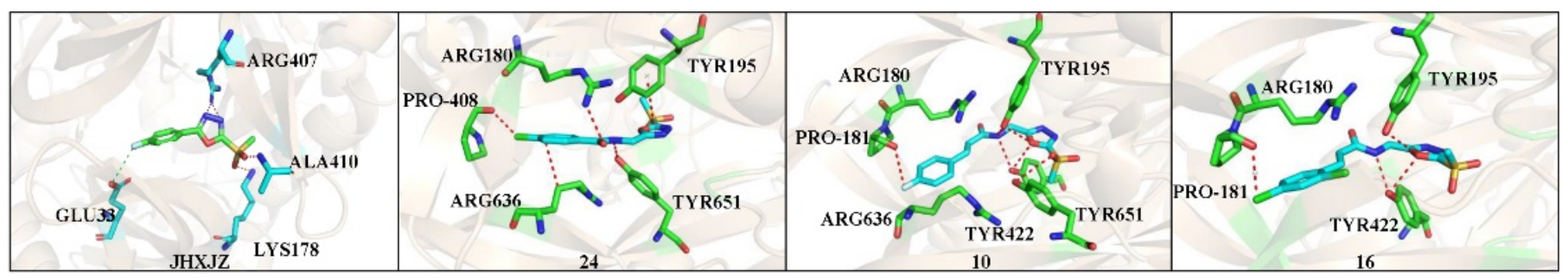

Figure 3. The binding modes of JHXJZ and compounds 24, 10, and 16.

\subsection{Chemicals}

The different substituted oxadiazole thioethers (intermediates 1a-2a) were prepared by glycine ethyl ester hydrochloride, di-tert-butyl carbonate, $\mathrm{N}_{2} \mathrm{H}_{4} \cdot \mathrm{H}_{2} \mathrm{O}, \mathrm{CS}_{2}$, bromide, and trifluoroacetic acid. Different acids containing aromatic groups were added to $\mathrm{SOCl}_{2}$ and refluxed to obtain intermediates $\mathbf{1 b} \mathbf{b} \mathbf{1 7 b}$. The intermediates $\mathbf{1} \mathbf{c}-\mathbf{2 6} \mathbf{c}$ were oxidized by $\left(\mathrm{NH}_{4}\right)_{6} \mathrm{Mo}_{7} \mathrm{O}_{24} \cdot 4 \mathrm{H}_{2} \mathrm{O}$ and hydrogen peroxide solution to obtain the target compounds 1-26 (Figure 4). The details of ${ }^{1} \mathrm{H}$ NMR, ${ }^{13} \mathrm{C}$ NMR, physicochemical property, melting point, yield, and HRMS are provided in the Supplementary Materials.
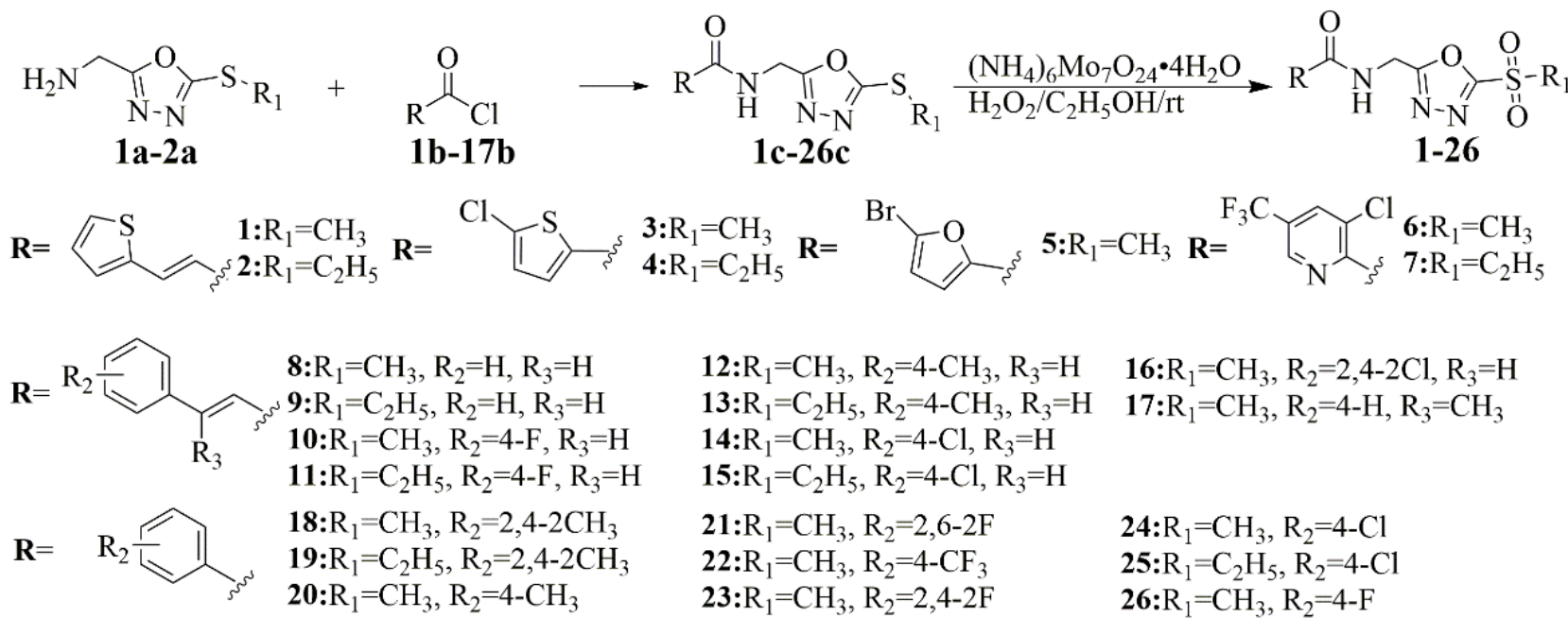

12: $\mathrm{R}_{1}=\mathrm{CH}_{3}, \mathrm{R}_{2}=4-\mathrm{CH}_{3}$,
13: $\mathrm{R}_{1}=\mathrm{C}_{2} \mathrm{H}_{5}, \mathrm{R}_{2}=4-\mathrm{CH}_{3}$
14: $\mathrm{R}_{1}=\mathrm{CH}_{3}, \mathrm{R}_{2}=4-\mathrm{Cl}, \mathrm{R}_{3}$
15: $\mathrm{R}_{1}=\mathrm{C}_{2} \mathrm{H}_{5}, \mathrm{R}_{2}=4-\mathrm{Cl}, \mathrm{R}$
21: $\mathrm{R}_{1}=\mathrm{CH}_{3}, \mathrm{R}_{2}=2,6-2 \mathrm{~F}$
22: $\mathrm{R}_{1}=\mathrm{CH}_{3}, \mathrm{R}_{2}=4-\mathrm{CF}_{3}$
23: $\mathrm{R}_{1}=\mathrm{CH}_{3}, \mathrm{R}_{2}=2,4-2 \mathrm{~F}$
16: $\mathrm{R}_{1}=\mathrm{CH}_{3}, \mathrm{R}_{2}=2,4-2 \mathrm{Cl}, \mathrm{R}_{3}=\mathrm{H}$

17: $\mathrm{R}_{1}=\mathrm{CH}_{3}, \mathrm{R}_{2}=4-\mathrm{H}, \mathrm{R}_{3}=\mathrm{CH}_{3}$

24: $\mathrm{R}_{1}=\mathrm{CH}_{3}, \mathrm{R}_{2}=4-\mathrm{Cl}$

25: $\mathrm{R}_{1}=\mathrm{C}_{2} \mathrm{H}_{5}, \mathrm{R}_{2}=4-\mathrm{Cl}$

26: $\mathrm{R}_{1}=\mathrm{CH}_{3}, \mathrm{R}_{2}=4-\mathrm{F}$

Figure 4. Synthesis route of compounds 1-26.

\subsection{Antibacterial Activity In Vitro Test}

All the target compounds showed excellent antibacterial activity against Xoo at 50 and $10 \mathrm{mg} / \mathrm{L}$ (Table S3). In addition to compounds 2 and 7, the antibacterial activity of all target compounds against Xoo was greater than $90 \%$ at $10 \mathrm{mg} / \mathrm{L}$. Interestingly, the antibacterial activity of compound 9 was $97.6 \%$ at $50 \mathrm{mg} / \mathrm{L}$. However, when the concentration was reduced to $10 \mathrm{mg} / \mathrm{L}$, the antibacterial activity of compound 9 was 100\%. This difference may be related to the solubility of compound 9. When the antibacterial activity was tested, we found that the solution with a concentration of $50 \mathrm{mg} / \mathrm{L}$ of compound 9 was turbid. However, the solution of compound 9 was transparent at $10 \mathrm{mg} / \mathrm{L}$. The $\mathrm{EC}_{50}$ values of compounds 1-26 against Xoo were $0.36-7.45 \mathrm{mg} / \mathrm{L}$, which were superior to those of bismerthiazol (83.07 mg/L) and thiodiazole copper $(113.38 \mathrm{mg} / \mathrm{L})$. Among them, 
24 compounds showed $\mathrm{EC}_{50}$ values less than $1.0 \mathrm{mg} / \mathrm{L}$. For example, the $\mathrm{EC}_{50}$ values of compounds 4, 10, 14, 15, 16, and 24 against Xoo were 0.45, 0.36, 0.43, 0.43, 0.42, and $0.40 \mathrm{mg} / \mathrm{L}$, respectively.

Meanwhile, all the target compounds showed good antibacterial activity against $X o c$ at 50 and $10 \mathrm{mg} / \mathrm{L}$ (Table S4). The antibacterial activity of compounds 1-26 was greater than $90 \%$ at $50 \mathrm{mg} / \mathrm{L}$. In addition, the $\mathrm{EC}_{50}$ values of compounds $\mathbf{1 - 2 6}$ against Xoc were $0.53-10.77 \mathrm{mg} / \mathrm{L}$, which were superior to those of bismerthiazol $(105.90 \mathrm{mg} / \mathrm{L})$ and thiodiazole copper $(131.54 \mathrm{mg} / \mathrm{L})$. Among them, 10 compounds showed $\mathrm{EC}_{50}$ values less than $1.0 \mathrm{mg} / \mathrm{L}$. For example, the $\mathrm{EC}_{50}$ values of compounds 8, 9, 10, 12, and 14 against $\mathrm{Xoc}$ were $0.70,0.78,0.53,0.64$, and $0.61 \mathrm{mg} / \mathrm{L}$, respectively.

\subsection{Antibacterial Activity In Vivo Test}

The antibacterial activity of compound $\mathbf{1 0}$ against RBLB and RBLS was evaluated (Figure S1 and Table 5). The protective activity of compound 10 against RBLB and RBLS was $43.2 \%$ and $53.6 \%$, respectively, which was superior to that of JHXJZ ( $34.1 \%$ and $26.4 \%$ ) and thiodiazole copper (33.0\% and 30.2\%). The curative activity of compound 10 against RBLB and RBLS was $44.5 \%$ and $51.7 \%$, respectively, which was superior to that of JHXJZ (32.6\% and $24.4 \%$ ) and thiodiazole copper (27.1\% and $28.6 \%$ ).

Table 5. Protective and curative activities of compound 10 against two rice bacterial diseases at $200 \mathrm{mg} / \mathrm{L}$.

\begin{tabular}{ccccc}
\hline & \multicolumn{2}{c}{ Rice Bacterial Leaf Blight } & \multicolumn{2}{c}{ Rice Bacterial Leaf Streak } \\
\cline { 2 - 5 } $\begin{array}{c}\text { Treatment } \\
\text { Group }\end{array}$ & $\begin{array}{c}\text { Protective } \\
\text { Activity (\%) }\end{array}$ & $\begin{array}{c}\text { Curative } \\
\text { Activity (\%) }\end{array}$ & $\begin{array}{c}\text { Protective } \\
\text { Activity (\%) }\end{array}$ & $\begin{array}{c}\text { Curative } \\
\text { Activity (\%) }\end{array}$ \\
\hline 10 & $43.2 \pm 5.8$ & $44.5 \pm 2.7$ & $53.6 \pm 1.8$ & $51.7 \pm 3.5$ \\
JHXJZ & $34.1 \pm 1.6$ & $32.6 \pm 1.5$ & $26.4 \pm 5.2$ & $24.4 \pm 2.2$ \\
BT & $39.8 \pm 1.6$ & $38.0 \pm 2.7$ & $47.4 \pm 3.5$ & $45.2 \pm 3.3$ \\
TC & $33.0 \pm 3.2$ & $27.1 \pm 3.1$ & $30.2 \pm 4.4$ & $28.6 \pm 5.0$ \\
\hline
\end{tabular}

\subsection{Enzyme Activity Detection of DLST}

DLST was found as the main target of JHXJZ in Xoo. JHXJZ may affect the cells by regulating the lysine succinyl modification level energy metabolism process $[17,18]$. The inhibitory activity of compound $\mathbf{1 0}$ on DLST was evaluated (Figure 5). After compound 10 treated Xoo and Xoc, the relative inhibition rates of DLST were $49.5 \%$ and $59.1 \%$ at $10 \mathrm{mg} / \mathrm{L}$, respectively. However, when the concentration was reduced to $1 \mathrm{mg} / \mathrm{L}$, the relative inhibition rates of DLST were $15.5 \%$ and $20.7 \%$, respectively.

\section{DLST activity of Xoo}

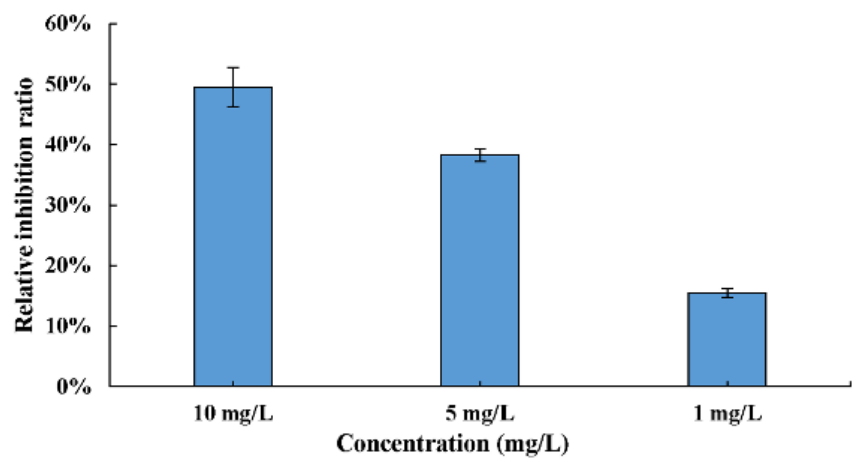

\section{DLST activity of Xoc}

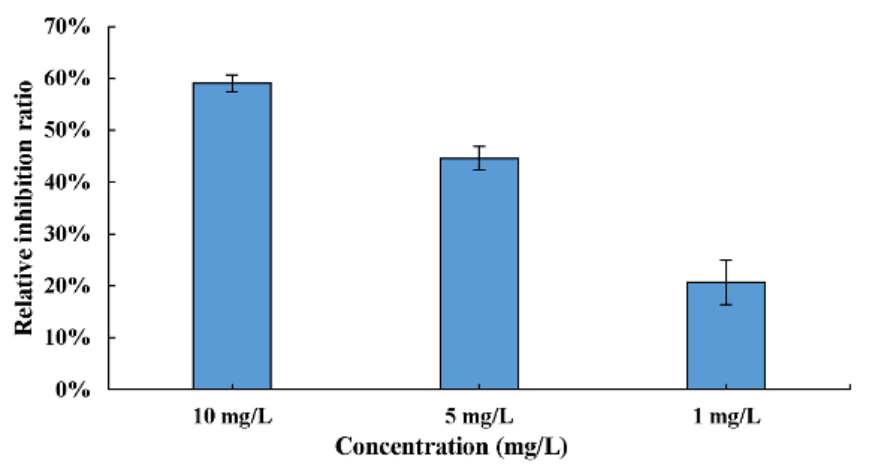

Figure 5. DLST activity of Xoo and Xoc at 10, 5, and $1 \mathrm{mg} / \mathrm{L}$. 


\subsection{Biofilm Formation}

The inhibitory activity of compound $\mathbf{1 0}$ on the biofilm formation of Xoo and Xoc was evaluated (Figure 6). At the concentrations of 10, 5, and $1 \mathrm{mg} / \mathrm{L}$, the inhibition rates of biofilm formation were $72.0 \%, 64.0 \%$, and $27.2 \%$, and $71.5 \%, 51.7 \%$, and $25.2 \%$, respectively. Therefore, compound $\mathbf{1 0}$ might affect the activity of bacteria through inhibiting the formation of biofilm.
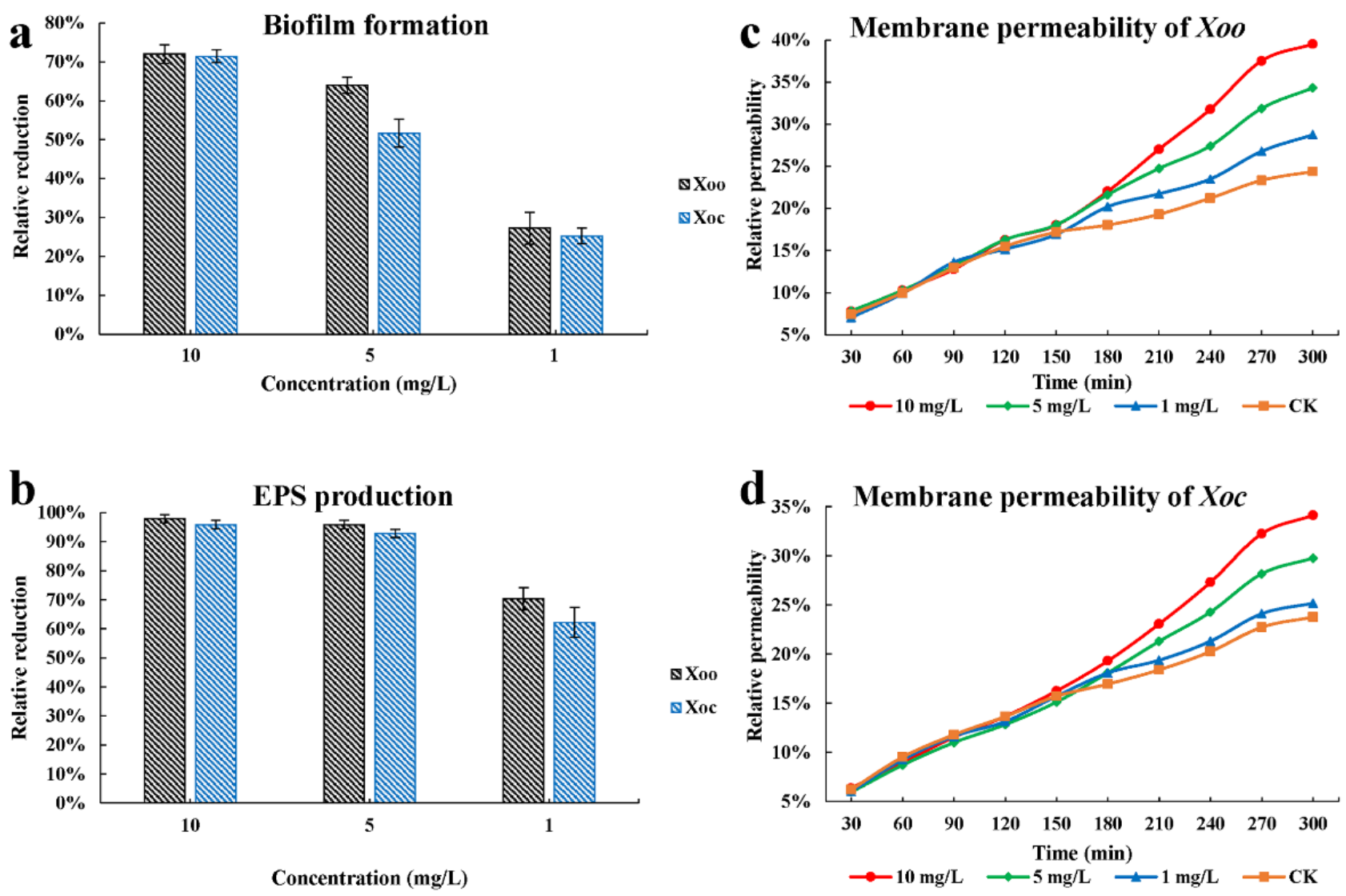

Figure 6. Effects of Xoo and Xoc on the biofilm formation (a), extracellular polysaccharide (EPS) production (b), and membrane permeability (c,d) at 10,5 , and $1 \mathrm{mg} / \mathrm{L}$.

\subsection{Extracellular Polysaccharide Production}

The inhibitory activity of compound $\mathbf{1 0}$ on the extracellular polysaccharide production of Xoo and Xoc was evaluated (Figure 6). The inhibition rates of extracellular polysaccharide production were $98.0 \%, 95.9 \%$, and $70.4 \%$, and $95.9 \%, 92.9 \%$, and $62.2 \%$ at 10,5 , and $1 \mathrm{mg} / \mathrm{L}$, respectively. Therefore, compound 10 might destroy the normal reproductive cycle of bacteria by inhibiting the production of extracellular polysaccharides.

\subsection{Membrane Permeability}

The effects of compound $\mathbf{1 0}$ on the cell membrane permeability of Xoo and Xoc at 10, 5 , and $1 \mathrm{mg} / \mathrm{L}$ were determined (Figure 6). After $30 \mathrm{~min}$, the cell membrane permeability increased as the treatment time increased. The cell membrane permeability of the different treatment groups and the negative control group did not differ before $180 \mathrm{~min}$. However, after $180 \mathrm{~min}$, the different treatment groups and the cell membrane permeability of the negative control group showed differential effects and had concentration dependence.

\subsection{Morphological Change in Bacteria}

The morphological changes of Xoo and Xoc were observed by the scanning electron microscope (Figure 7). The cell shapes of the negative control groups of Xoo and Xoc were full and there were no obvious wrinkles on the surface. At the concentrations of 1,5 , and 
$10 \mathrm{mg} / \mathrm{L}$ of compound 10, wrinkles and deformations appeared on the cell surface, and the degree of wrinkles and deformation gradually increased as the concentration increased.

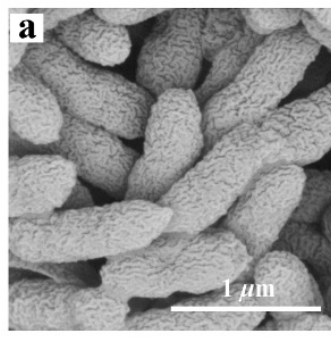

Negative control

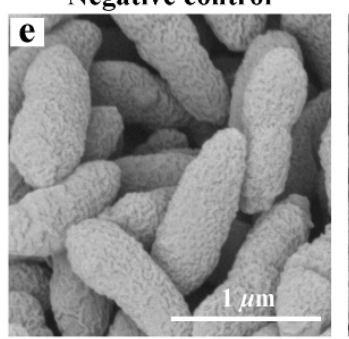

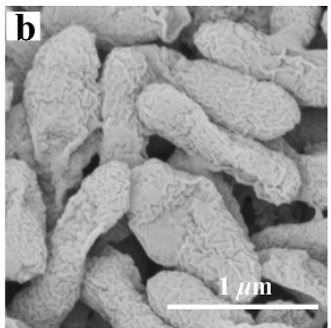

$1 \mathrm{mg} / \mathrm{L}$

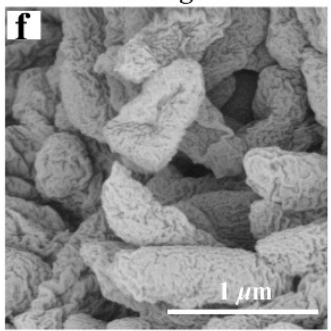

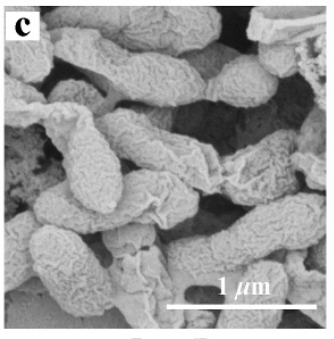

$5 \mathrm{mg} / \mathrm{L}$

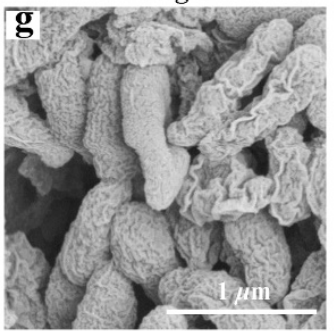

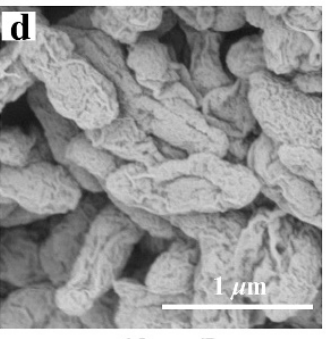

$10 \mathrm{mg} / \mathrm{L}$

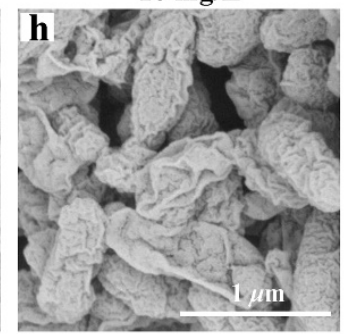

Figure 7. Changes in bacterial morphology of Xoo (a-d) and Xoc (e-h) at 10, 5, and $1 \mathrm{mg} / \mathrm{L}$.

\section{Discussion}

In summary, via fragment-based virtual screening, a series of new oxadiazole sulfone derivatives was synthesized to screen high-efficiency antibacterial agents for rice bacterial diseases. Interestingly, all synthetic target compounds showed excellent antibacterial activities against Xoo and Xoc. Compound 10 showed good antibacterial activity in vivo against RBLB and RBLS. Compound $\mathbf{1 0}$ showed good inhibitory activity against DLST, which indicated that DLST might be the target of compound 10 in Xoo and Xoc. In addition, compound 10 might suppress the growth of Xoo and Xoc by inhibiting the formation of biofilm and the production of extracellular polysaccharides and changing the cell membrane permeability and cell surface morphology. The method of compounds' structural design based on fragment virtual screening can improve the efficiency of finding highly active compounds. In addition, compound $\mathbf{1 0}$ can be studied as a potential antibacterial agent in the future.

\section{Materials and Methods}

\subsection{Molecular Design}

\subsubsection{Molecular Docking and Dynamics Simulation}

Molecular docking was performed using AutoDock 4.2. The protein crystal was generated on BLAST in Uniprot (A0A0K0GL90) and built by Swiss-Model [19,20]. The homology modeling template 1C4T showed $65.8 \%$ sequence identity [21]. The protein structures were prepared by removing the water molecules and then adding hydrogen atoms and repairing the side chains. JHXJZ was docked into DLST, and 10 poses were exported for further analysis. The molecular dynamic was performed using AMBER 16 [22]. The dominant conformation was confirmed by $10 \mathrm{~ns}$ of dynamic trajectory analysis, and the binding energy calculation was conducted via the MM-PBSA method [23].

\subsubsection{Fragment-Based Virtual Screening}

Fragment-based virtual screening was performed using the ACFIS web server (http:/ / chemyang.ccnu.edu.cn/ccb/server/ACFIS/ 11 January 2021). The selected compound, in combination with DLST as the starting structure, was linked to the refined database containing over 1500 fragments. The $\Delta G$ value of each newly generated compound was calculated by the MM-PBSA method after a minimization. 


\subsubsection{Ligand-Directing Evolution}

The ligand-directing evolution was performed using the AILDE web server (http: / / chemyang.ccnu.edu.cn/ccb/server/AILD 15 January 2021) based on the result of the fragment virtual screening. Every hydrogen atom of the selected favored fragment was replaced by the 10 most used substituents $\left(-\mathrm{CH}_{3},-\mathrm{OH},-\mathrm{F},-\mathrm{Cl},-\mathrm{Br},-\mathrm{CONH}_{2},-\mathrm{CF}_{3},-\mathrm{NH}_{2}\right.$, $-\mathrm{NO}_{2}$, and $-\mathrm{OCH}_{3}$ ) to generate the potential compounds in each snapshot. We used the MD simulation to refine the newly generated receptor-ligand complex to obtain the final structure. The binding free energy $(\Delta G)$ of the refined complex structures was evaluated using the MM-PBSA method.

\subsection{Chemicals}

The synthesis processes of the intermediates and target compounds were supervised through thin-layer chromatography (TLC). Using an XT-4 binocular microscope (Beijing Tech Instrument Co., Beijing, China), the melting points were measured. ${ }^{13} \mathrm{C}$ and ${ }^{1} \mathrm{H}$ NMR spectra were obtained by a Bruker Ascend-400 spectrometer (Bruker, Karlsruhe, Germany). The HRMS data were acquired by a Thermo Scientific Q Exactive (Thermo Scientific, Waltham, MA, USA).

General Procedures for the Preparation of Compounds 1-26. The different oxadiazole intermediates 1a-2a were synthesized according to known methods [23]. Different acids containing aromatic groups were added to $\mathrm{SOCl}_{2}(5-8 \mathrm{~mL})$ and refluxed for $5-8 \mathrm{~h}$ to obtain intermediates $\mathbf{1 b} \mathbf{- 1 7} \mathbf{b}$. Next, the triethylamine $(3.8 \mathrm{mmol})$ and intermediates 1a-2a $(2.5 \mathrm{mmol})$ were added to $\mathrm{CH}_{2} \mathrm{Cl}_{2}$ in ice-water bath conditions. The intermediates $\mathbf{1 b}-\mathbf{1 7} \mathbf{b}$ were added and stirred for $2.5-5 \mathrm{~h}$. Then, the intermediates $\mathbf{1 c}-\mathbf{2 6 c}$ were obtained by silica gel column chromatography. Finally, the intermediates 1c-26c $(1.5 \mathrm{mmol})$, $\left(\mathrm{NH}_{4}\right)_{6} \mathrm{Mo}_{7} \mathrm{O}_{24} \cdot 4 \mathrm{H}_{2} \mathrm{O}(0.3 \mathrm{mmol})$, and hydrogen peroxide solution $(30 \%, 15 \mathrm{mmol})$ were admixed and stirred at $25^{\circ} \mathrm{C}$ for $3-8 \mathrm{~h}$. The saturated ice saltwater was added to the wash, and the target compounds 1-26 were obtained with a yield of 52-89\% (Figure 4). The details of compounds 1-26 can be found in the Supplementary Materials.

\subsection{Antibacterial Activity In Vitro Test}

The antibacterial activities in vitro of compounds 1-26 against Xoo and Xoc were evaluated according to our previously reported method [24]. The compounds were dissolved in DMSO, and the solutions were diluted with $0.1 \%$ Tween 20 and nutrient broth $(\mathrm{NB}, 1 \%)$ media to prepare different concentrations of the solutions. After shaking the bacteria at $28{ }^{\circ} \mathrm{C}$ for $1-2 \mathrm{~d}$, the inhibition rates were calculated-by comparing differences of the $\mathrm{OD}_{595}$ values between the treatment group and negative controls by a microplate spectrophotometer. The test was repeated three times.

\subsection{Antibacterial Activity In Vivo Test}

The antibacterial activities of compound 10 against RBLB and RBLS were evaluated at $200 \mathrm{mg} / \mathrm{L}$ using the leaf-cutting and needleless injector method according to the reported method [25]. The NB (1\%) media containing Xoo and Xoc at the logarithmic growth period were inoculated on rice leaves. In the protective activity, the agent was sprayed onto rice blades, and bacteria were inoculated after $24 \mathrm{~h}$. In the curative activity, the bacteria were inoculated into the rice leaves, and the test compounds were sprayed after $24 \mathrm{~h}$. The antibacterial activities were calculated by the disease index and lesion length of rice leaves at 2 weeks post-spraying.

\subsection{Enzyme Activity Detection of DLST}

The inhibitory activity of compound $\mathbf{1 0}$ against DLST was tested according to the previously reported method and the instructions of the enzyme activity kit $[17,18]$. The Xoo and Xoc bacteria solutions at the logarithmic growth period were added to the NB medium $\left(5 \mathrm{~mL}\right.$ ) and shaken at $28{ }^{\circ} \mathrm{C}$ until the $\mathrm{OD}_{600}$ value reached 0.3. Compound $\mathbf{1 0}$ and JHXJZ, at the final concentrations of 10,5 , and $1 \mathrm{mg} / \mathrm{L}$, were mixed into the bacterial suspension, 
and the mixture was continuously shaken for $12 \mathrm{~h}$. The solution without the compound was used as the negative control in the same experimental conditions. Xoo and Xoc were cultivated to a logarithmic growth phase (the negative control). Then, the bacterial solution was collected by centrifugation. The DLST proteins of Xoo and Xoc were extracted by the method described in the kit. Soon afterward, the enzyme activity of DLST was tested by a microplate spectrophotometer (Shanghai Enzyme Link Biotechnology Co., Ltd. Suzhou, China) using the enzyme assays kits.

\subsection{Biofilm Formation}

The effects of compound $\mathbf{1 0}$ on the biofilm formation of Xoo and Xoc were determined according to the previously reported method [26]. Compound 10 and bacteria with a logarithmic growth phase were mixed to prepare solutions of 10,5, and $1 \mathrm{mg} / \mathrm{L}$, respectively. The bacteria were poured out after standing for $5 \mathrm{~d}$ at $28{ }^{\circ} \mathrm{C}$. Next, the crystalline violet $(0.1 \%, w / v)$ was added. The ethanol $(2 \mathrm{~mL})$ was added to dissolve the crystal violet on the bottle wall. The inhibition activities were calculated by the difference in the $\mathrm{OD}_{590}$ values.

\subsection{Membrane Permeability}

The effects of compound $\mathbf{1 0}$ on the membrane permeability of Xoo and Xoc were tested according to the previously reported works $[27,28]$. Xoo and Xoc, both with a logarithmic growth phase, were collected by centrifugation. Compound $\mathbf{1 0}$ was prepared as solutions of 10,5 and $1 \mathrm{mg} / \mathrm{L}$, respectively, and the conductivities were measured at 0-300 min.

\subsection{Extracellular Polysaccharide Production}

According to our previously reported work, the effects of compound $\mathbf{1 0}$ on the extracellular polysaccharide (EPS) production of Xoo and Xoc were tested at 10, 5, and $1 \mathrm{mg} / \mathrm{L}$ [29]. After shaking at $28{ }^{\circ} \mathrm{C}$ for $3 \mathrm{~d}$, the bacteria were centrifuged, and anhydrous ethanol was added to obtain the deposit after $12 \mathrm{~h}$. The EPS production was acquired by centrifugation, drying, and weighing.

\subsection{Morphological Change in Bacteria}

According to the previously reported method [30-32], the changes in bacterial cell morphology were observed via scanning electron microscopy (FEI, Hillsboro, OR, USA). The details of the assay were adequately described in the published previous paper.

Supplementary Materials: The following are available online at https: / www.mdpi.com/article / $10.3390 / \mathrm{ijms} 222312953 / \mathrm{s} 1$.

Author Contributions: J.C., C.W. and J.H. conceived and designed the experiments; the calculation part was performed by J.H.; the experiments were performed by C.W., Y.C., X.L. and Y.W.; J.C., Z.W., S.W. and C.W. analyzed and interpreted the data; C.W. wrote the paper; J.C. critically revised the paper with regard to important intellectual content. All authors have read and approved the final version of the manuscript.

Funding: This research was funded by the Natural Science Foundation of Guizhou University [NO. (2021)01], Cultivation Project of Guizhou University [NO. (2020)06], and the Program of Introducing Talents of Discipline to Universities of China (111 Program, D20023).

Data Availability Statement: Characterizations, physical, analytical, and bactericidal activity data of target compounds 1-26 were showed in Supplementary Materials.

Acknowledgments: We gratefully acknowledge the assistance from the Natural Science Foundation of Guizhou University [NO. (2021)01], Cultivation Project of Guizhou University [NO. (2020)06], and the Program of Introducing Talents of Discipline to Universities of China (111 Program, D20023).

Conflicts of Interest: The authors declare no conflict of interest. 


\begin{abstract}
Abbreviations
NMR, nuclear magnetic resonance; HRMS, high-resolution mass spectrometry; MM/PBSA, molecular mechanics/Poisson-Boltzman surface area; LE, ligand efficiency; FBDD, fragment-based drug discovery.
\end{abstract}

\title{
References
}

1. Zou, L.F.; Li, Y.R.; Chen, G.Y. A non-marker mutagenesis strategy to generate poly-hrp gene mutants in the rice pathogen Xanthomonas oryzae pv. oryzicola. Agric. Sci. China 2011, 10, 1139-1150. [CrossRef]

2. Wu, S.K.; Shi, J.; Chen, J.X.; Hu, D.Y.; Zang, L.S.; Song, B.A. Synthesis, antibacterial activity, and mechanisms of novel 6-sulfonyl1,2,4-triazolo[3,4-b][1,3,4]thiadiazole derivatives. J. Agric. Food Chem. 2021, 69, 4645-4654. [CrossRef]

3. Jiang, S.; He, M.; Xiang, X.W.; Adnan, M.; Cui, Z.N. Novel sthiazol-2-yl-furan-2-carbothioate derivatives as potential T3SS inhibitors against Xanthomonas oryzae on rice. J. Agric. Food Chem. 2019, 67, 11867-11876. [CrossRef] [PubMed]

4. Mansfield, J.; Genin, S.; Magori, S.; Citovsky, V.; Sriariyanum, M.; Ronald, P.; Dow, M.; Verdier, V.; Beer, S.V.; Machado, M.A.; et al. Top 10 plant pathogenic bacteria in molecular plant pathology. Mol. Plant Pathol. 2012, 13, 614-629. [CrossRef] [PubMed]

5. Liu, W.D.; Liu, J.L.; Triplett, L.; Leach, J.E.; Wang, G.L. Novel insights into rice innate immunity against bacterial and fungal pathogens. Annu. Rev. Phytopathol. 2014, 52, 213-241. [CrossRef] [PubMed]

6. Li, P.; Tian, P.Y.; Chen, Y.Z.; Song, X.P.; Xue, W.; Jin, L.H.; Hu, D.Y.; Yang, S.; Song, B.A. Novel bisthioether derivatives containing a 1,3,4-oxadiazole moiety: Design, synthesis, antibacterial and nematocidal activities. Pest Manag. Sci. 2018, 74, 844-852. [CrossRef]

7. Sundin, G.W.; Castiblanco, L.F.; Yuan, X.C.; Zeng, Q.; Yang, C.H. Bacterial disease management: Challenges, experience, innovation and future prospects. Mol. Plant Pathol. 2016, 17, 1506-1518. [CrossRef]

8. Lin, Y.J.; He, Z.L.; Rosskopf, E.N.; Conn, K.L.; Powell, C.A.; Lazarovits, G. A nylon membrane bag assay for determination of the effect of chemicals on soilborne plant pathogens in soil. Plant Dis. 2010, 94, 201-206. [CrossRef]

9. Zhao, S.S.; Xiao, C.; Wang, J.J.; Tian, K.L.; Ji, W.X.; Yang, T.T.; Khan, B.; Qian, G.L.; Yan, W.; Ye, Y.H. Discovery of natural fabH inhibitors using an immobilized enzyme column and their antibacterial activity against Xanthomonas oryzae pv. oryzae. J. Agric. Food Chem. 2020, 68, 14204-14211. [CrossRef]

10. Li, P.; Shi, L.; Yang, X.; Yang, L.; Chen, X.W.; Wu, F.; Shi, Q.C.; Xu, W.M.; He, M.; Hu, D.Y.; et al. Antibacterial activities against rice bacterial leaf blight and tomato bacterial wilt of 2-mercapto-5-substituted-1,3,4-oxadiazole/ thiadiazole derivatives. Bioorg. Med. Chem. Lett. 2014, 24, 1677-1680. [CrossRef]

11. Wu, F.X.; Zhuo, L.S.; Wang, F.; Huang, W.; Hao, G.F.; Yang, G.F. Auto in silico ligand directing evolution (AILDE) to facilitate the rapid and efficient discovery of drug lead. iScience 2020, 23, 101179. [CrossRef]

12. Zhavoronkov, A.; Ivanenkov, Y.A.; Aliper, A.; Veselov, M.S.; Aladinskiy, V.A.; Aladinskaya, A.V.; Terentiev, V.A.; Polykovskiy, D.A.; Kuznetsov, M.D.; Asadulaev, A.; et al. Deep learning enables rapid identification of potent DDR1 kinase inhibitors. Nat. Biotechnol. 2019, 37, 1038-1040. [CrossRef]

13. Shang, J.X. Application of computer aided drug design in the research and development of natural product multi-target drugs. Smart Healthc. 2019, 5, 83-87. [CrossRef]

14. Seahan, G.; Kanagasabai, S.; Ananthasri, S.; Kannappan, B.; Kothandan, G. Insights of structure-based pharmacophore studies and inhibitor design against Gal3 receptor through molecular dynamics simulations. J. Biomol. Struct. Dyn. 2020, 39, 6987-6999. [CrossRef]

15. Ren, J.; Li, J.; Shi, F.; Wang, X.; He, J.H.; Xu, Y.C.; Zhang, N.X.; Xiong, B.; Shen, J.K. Progress in the fragment-based drug discovery. Acta Pharm. Sin. 2013, 48, 14-24. [CrossRef]

16. Li, P.; Yin, J.; Xu, W.M.; Wu, J.; He, M.; Hu, D.Y.; Yang, S.; Song, B.A. Synthesis, antibacterial activities, and 3D-QSAR of sulfone derivatives containing 1,3,4-oxadiazole moiety. Chem. Biol. Drug Des. 2013, 82, 546-556. [CrossRef] [PubMed]

17. Chen, B.; Long, Q.S.; Zhao, Y.L.; Wu, Y.Y.; Ge, S.S.; Wang, P.Y.; Yang, C.J.; Chi, Y.G.; Song, B.A.; Yang, S. Sulfone-based probes unraveled dihydrolipoamide $S$-succinyltransferase as an unprecedented target in phytopathogens. J. Agric. Food Chem. 2019, 67, 6962-6969. [CrossRef] [PubMed]

18. Chen, B.; Long, Q.S.; Meng, J.; Zhou, X.; Wu, Z.B.; Tuo, X.X.; Ding, Y.; Zhang, L.; Wang, P.Y.; Li, Z.; et al. Target discovery in ralstonia solanacearum through an activity-based protein profiling technique based on bioactive oxadiazole sulfones. J. Agric. Food Chem. 2020, 68, 2340-2346. [CrossRef]

19. Waterhouse, A.; Bertoni, M.; Bienert, S.; Studer, G.; Tauriello, G.; Gumienny, R.; Heer, F.T.; de Beer, T.A.P.; Rempfer, C.; Bordoli, L.; et al. SWISS-MODEL: Homology modelling of protein structures and complexes. Nucleic Acids Res. 2018, 46, 296-303. [CrossRef] [PubMed]

20. Guex, N.; Peitsch, M.C.; Schwede, T. Automated comparative protein structure modeling with SWISS-MODEL and SwissPdbViewer: A historical perspective. Electrophoresis 2009, 30, 162-173. [CrossRef] [PubMed]

21. James, E.K.; Donald, C.; Janet, E.L.; Stephen, R.E.; Lester, J.R.; Marvin, L.H. Expression, purification, and structural analysis of the trimeric form of the catalytic domain of the escherichia coli dihydrolipoamide succinyltransferase. Prot. Sci. 2000, 9, 37-48. [CrossRef] 
22. Case, D.A.; Betz, R.M.; Cerutti, D.S.; Cheatham, T.E.; Darden, T.A.; Duke, R.E.; Kollman, P.A. AMBER 16; University of California: San Francisco, CA, USA, 2016. [CrossRef]

23. Wei, C.Q.; Huang, J.J.; Luo, Y.Q.; Wang, S.B.; Wu, S.K.; Xing, Z.F.; Chen, J.X. Novel amide derivatives containing an imidazo [1,2-a] pyridine moiety: Design, synthesis as potential nematicidal and antibacterial agents. Pestic. Biochem. Phys. 2021, 175, 104857. [CrossRef] [PubMed]

24. Wang, S.B.; Gan, X.H.; Wang, Y.J.; Li, S.Y.; Yi, C.F.; Chen, J.X.; He, F.C.; Yang, Y.Y.; Hu, D.Y.; Song, B.A. Novel 1,3,4-oxadiazole derivatives containing a cinnamic acid moiety as potential bactericide for rice bacterial diseases. Int. J. Mol. Sci. 2019, 20, 1020. [CrossRef] [PubMed]

25. Wu, Z.B.; Shi, J.; Chen, J.X.; Hu, D.Y.; Song, B.A. Design, synthesis, antibacterial activity, and mechanisms of novel 1,3,4-thiadiazole derivatives containing an amide moiety. J. Agric. Food Chem. 2021, 69, 8660-8670. [CrossRef]

26. Yi, C.F.; Chen, J.X.; Wei, C.Q.; Wu, S.K.; Wang, S.B.; Hu, D.Y.; Song, B.A. $\alpha$-Haloacetophenone and analogues as potential antibacterial agents and nematicides. Bioorg. Med. Chem. Lett. 2020, 30, 126824. [CrossRef]

27. Yang, J.; Chen, Y.Z.; Xuan, W.Y.; Tao, L.; Zhang, Y.D.; Wang, S.R.; Zhang, G.C.; Zhang, J. Inhibitory effects and mechanisms of vanillin on gray mold and black rot of cherry tomatoes. Pestic. Biochem. Phys. 2021, 175, 104859. [CrossRef]

28. Xiang, J.; Liu, D.Y.; Chen, J.X.; Hu, D.Y.; Song, B.A. Design and synthesis of novel 1,3,4-oxadiazole sulfone compounds containing 3,4-dichloroisothiazolylamide moiety and evaluation of rice bacterial activity. Pestic. Biochem. Phys. 2020, 170, 104695. [CrossRef]

29. Shi, L.; Li, P.; Wang, W.L.; Gao, M.N.; Wu, Z.X.; Song, X.P.; Hu, D.Y. Antibacterial activity and mechanism of action of sulfone derivatives containing 1,3,4-oxadiazole moieties on rice bacterial leaf blight. Molecules 2015, 20, 11660-11675. [CrossRef]

30. Zhou, J.; Tao, Q.Q.; Wang, P.Y.; Shao, W.B.; Wu, Z.B.; Li, Z.; Yang, S. Antimicrobial evaluation and action mechanism of pyridinium-decorated 1,4-pentadien-3-one derivatives. Bioorg. Med. Chem. Lett. 2018, 28, 1742-1746. [CrossRef]

31. Jiang, S.C.; Su, S.J.; Chen, M.; Peng, F.; Zhou, Q.; Liu, T.T.; Liu, L.W.; Xue, W. Antibacterial activities of novel dithiocarbamatecontaining 4H-chromen-4-one derivatives. J. Agric. Food Chem. 2020, 68, 5641-5647. [CrossRef]

32. Mou, H.L.; Shi, J.; Chen, J.X.; Hu, D.Y. Synthesis, antibacterial activity and mechanism of new butenolides derivatives containing an amide moiety. Pestic. Biochem. Phys. 2021, 178, 104913. [CrossRef] [PubMed] 